\title{
Effects of training and support programs for leaders of illness-based support groups: commentary and updated evidence
}

\author{
Kimberly A. Turner ${ }^{1,2}$, Danielle B. Rice ${ }^{1,3}$, Andrea Carboni-Jiménez ${ }^{1}$, Jill Boruff ${ }^{4}$ and Brett D. Thombs ${ }^{1,2,3,5,6,7^{*}}$ (D
}

\begin{abstract}
Background: Peer-led support groups play an important role in supporting people with chronic diseases. They may be particularly important for people with rare diseases who typically do not have access to professional support options that focus on their disease-specific needs. Many peer-led support groups in rare diseases, however, are not sustained, and many patients do not have access to support groups. Training and education for peer support group leaders could address barriers to initiating and sustaining groups, but there is little evidence on the effectiveness of support group leader training programs. A previous systematic review evaluated the effects of training programs for peer leaders of support groups for people with medical illness on leader and support group outcomes, but it identified only one randomized controlled trial (RCT) that compared high- and low-resource training programs for cancer support group leaders. The trial did not find evidence that the high-resource program was more effective, but was limited by a small sample size and serious methodological limitations. To meet the needs of people living with the rare autoimmune connective tissue disease scleroderma, the Scleroderma Patientcentered Intervention Network has partnered with patient organizations to develop the Scleroderma Support group Leader EDucation Program, and a full-scale RCT to test the effectiveness of the program is planned. To verify the need for such a trial, we updated the previous systematic review.

Updated evidence: Review methods for the update were unchanged from the initial review. The updated database search yielded 1504 unique citations in addition to the 9757 assessed for eligibility in the previous review. All additional citations identified in the updated search were excluded the title and abstract review stage.

Conclusions: Our systematic review update found that there is presently insufficient evidence on the effectiveness of training and support programs for peer leaders of disease-based support groups, highlighting the need for welldesigned and rigorously conducted RCTs to examine the effects of training for peer leaders of support groups, especially in a rare disease context. The Scleroderma Patient-centered Intervention Network's trial of the Scleroderma Support group Leader EDucation Program will serve as such a trial.
\end{abstract}

Systematic review registration: PROSPERO CRD42018096369

Keywords: Support groups, Leader training programs, Peer support, Peer leaders, Systematic review

\footnotetext{
* Correspondence: brett.thombs@mcgill.ca

${ }^{1}$ Lady Davis Institute of the Jewish General Hospital, 4333 Cote Ste Catherine

Road, Montréal, Québec H3T 1E4, Canada

${ }^{2}$ Department of Psychiatry, McGill University, Montreal, Quebec, Canada

Full list of author information is available at the end of the article
}

(c) The Author(s). 2019 Open Access This article is distributed under the terms of the Creative Commons Attribution 4.0 International License (http://creativecommons.org/licenses/by/4.0/), which permits unrestricted use, distribution, and reproduction in any medium, provided you give appropriate credit to the original author(s) and the source, provide a link to the Creative Commons license, and indicate if changes were made. The Creative Commons Public Domain Dedication waiver (http://creativecommons.org/publicdomain/zero/1.0/) applies to the data made available in this article, unless otherwise stated. 


\section{Background}

Illness-based support groups serve as an important source of support and education for many people with chronic medical illnesses [1-3]. Support group leaders have an integral role in determining the success and sustainability of these groups $[4,5]$. Peer-led support groups often have an especially important role in supporting people with rare diseases, who typically do not have access to specialized support options through the health care system $[6,7]$.

Most peer leaders of support groups, however, do not receive any training. In a previous systematic review published in 2016 [8], we searched for evidence on whether training programs for peer leaders of support groups for people with medical illnesses (1) increase the competency and self-efficacy of leaders and (2) improve health outcomes and satisfaction with support groups among support group members. We searched for evidence through April 8, 2016, but identified only one randomized controlled trial (RCT) that met the inclusion criteria [9]. That trial compared the effects of a 2-day face-to-face group training workshop and 4-month access to a website and discussion forum $(N=29$; high resource) to 4 months of website access and discussion forum alone $(N=23$; low resource). The RCT did not find evidence that the high-resource program was more effective. However, the trial was substantially underpowered, not enough information was provided to determine the content of the intervention or how it was delivered, and risk of bias was rated as high due to methodological limitations [8].

\section{A training program for leaders of scleroderma support groups}

Systemic sclerosis (SSc), or scleroderma, is a rare, chronic, autoimmune connective tissue disease characterized by abnormal fibrotic processes and excessive collagen production [10-12]. SSc is an example of a rare disease where peer-led support groups play an important role in helping people manage the impact of their disease [13-17]. Currently, there are between 150 and 200 active SSc support groups affiliated with Scleroderma Canada and the Scleroderma Foundation in the USA, most of which are led by people living with the disease $[18,19]$. There are also support group networks in other countries. As is common in rare diseases, however, many people with SSc do not have access to SSc support groups, and many support groups that are initiated are not sustained due to a number of obstacles, some of which could be addressed by providing training to patient support group leaders [13-17].

To meet the needs of SSc patients, the Scleroderma Patient-centered Intervention Network (SPIN) [6, 20] partnered with SSc patient organizations to develop the Scleroderma Support group Leader EDucation (SPIN-SSLED) Program. The SPIN-SSLED Program is a 3-month long, 13-module, group training program that is delivered using videoconferencing in order to provide information and skills to improve patient support group leaders' confidence and self-efficacy to carry out their leadership roles. Recently, SPIN undertook a feasibility trial of the program (NCT03508661), and a full-scale RCT is planned. To verify the need for such a trial, we updated our previous systematic review [8].

\section{Updated evidence}

The objective of the systematic review update was to seek updated evidence on effectiveness of training and support programs for peer leaders of support groups for people with medical illnesses on (1) the competency and self-efficacy of group leaders and (2) self-efficacy for disease management, health outcomes, and satisfaction with the support group experience among group members compared to inactive control groups and alternative training programs. A systematic review update was registered in PROSPERO (CRD42018096369). Review methods were unchanged from the initial review, which can be accessed via the open access publication (https:// bmjopen.bmj.com/content/6/11/e013325.long) [8]. The updated search was done from the beginning of April 1, 2016, to June 4, 2018. The complete search strategy can be found in Additional file 1. The updated database search yielded 1504 unique article citations in addition to the 9757 assessed for eligibility in the previous review. See Fig. 1 for the updated PRISMA flowchart. All additional citations identified in the updated search were excluded at the title and abstract review stage. No additional eligible studies were identified via manual searching of the reference list of the included publication, by searching trial registries, or by citation tracking.

\section{Future directions}

The original systematic review, which was published in 2016, did not identify any trials that compared peer support group leader training and support programs to no-training comparators. It identified one RCT that evaluated the effects of alternative training program resources [9]. That study did not report any statistically significant differences between the two training groups they evaluated, but only 65 support group leaders were randomized, the training programs provided were not well described, and there were risk of bias concerns across multiple domains [8]. The updated systematic review did not identify any additional evidence for inclusion.

There is a need for well-designed and rigorously conducted RCTs to examine the effects of training for peer 


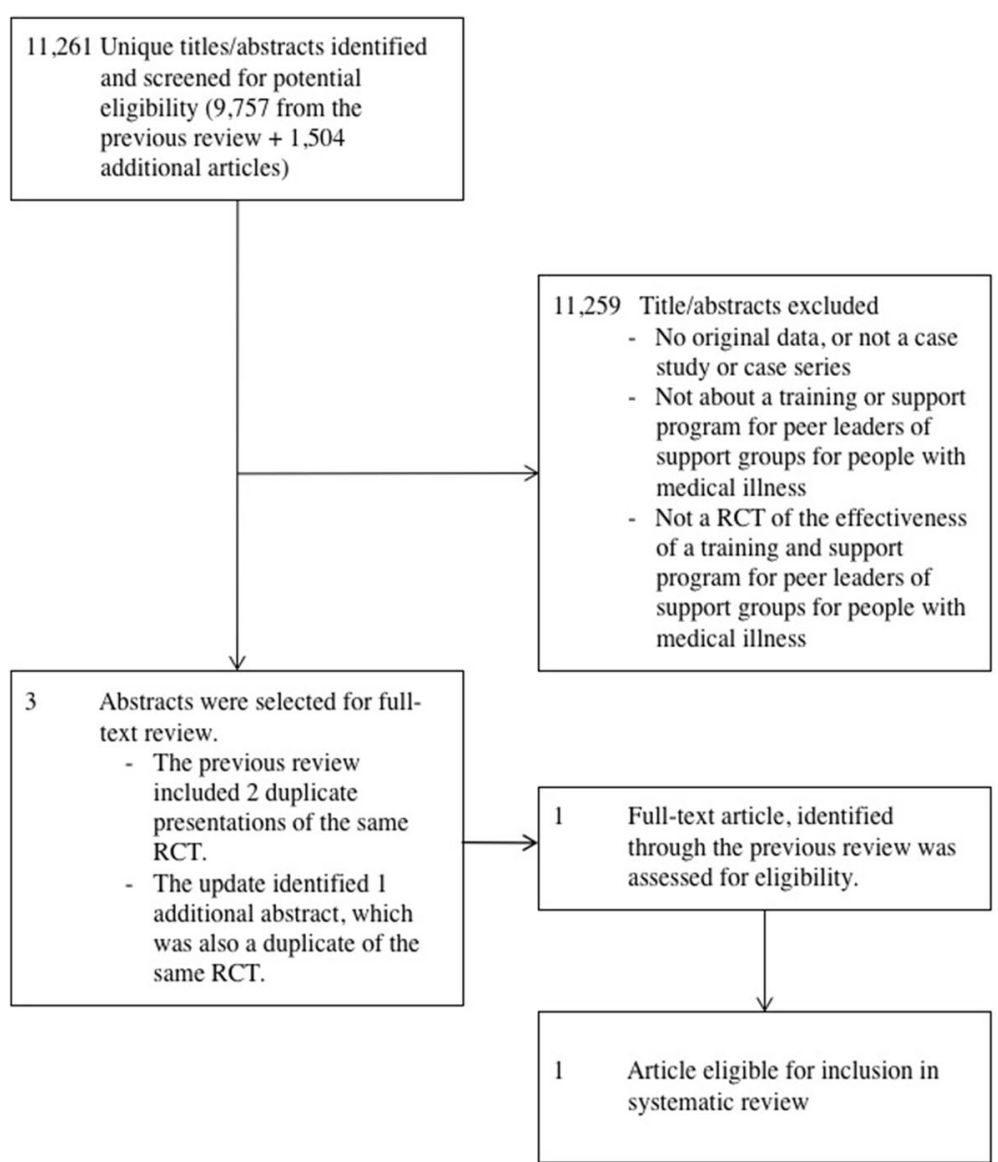

Fig. 1 Updated PRISMA flowchart

leaders of support groups, especially in a rare disease context. Thus, SPIN has partnered with patient organizations, including Scleroderma Canada, the Scleroderma Foundation (USA), Scleroderma \& Raynaud's UK, and the Scleroderma Association of New South Wales (Australia) to develop and test the SPIN-SSLED Program, which is a videoconference-based training and education program, designed to improve skills and self-efficacy, reduce burden, and improve emotional and physical function among support group leaders. A Scleroderma Patient Advisory Team, comprised of current SSc peer support group leaders, and representatives from SSc patient organizations collaborated with a team consisting of researchers in SSc to develop the program. The program uses a learner-centered, problembased learning approach that integrates theory and practice by first presenting relevant knowledge and skills, then presenting a real-world problem and working to identify solutions [21, 22]. The program consists of 13 modules delivered via weekly group videoconference sessions over the course of 3 months. Each session is approximately 60-90 min. A successful feasibility trial of the SPIN-SSLED Program was recently conducted
(NCT03508661). Results informed revisions to the content of the program and provided confidence that the program can be effectively and efficiently delivered in a full-scale trial. The planned full-scale SPIN-SSLED trial, which was recently funded by the Canadian Institutes of Health Research, is scheduled to begin in 2019 (http://webapps.cihr-irsc.gc.ca/decisions/p/project_details.html?applId=388187\&lang=en).

\section{Conclusions}

In summary, peer-led support groups play an important role in supporting those who do not have access to professional support to provide educational and coping resources, which is often the case in rare diseases such as SSc. Our systematic review update found that there is presently insufficient evidence on the effectiveness of training and support programs for peer leaders of disease-based support groups. The SPIN-SSLED trial is intended to fill this knowledge gap by testing a program that is designed for support group leaders with the rare autoimmune disease scleroderma, but, if successful, will be easily adapted for other patient groups. 


\section{Additional file}

Additional file 1: Search strategies. (DOCX $14 \mathrm{~kb}$ )

\begin{abstract}
Abbreviations
PRISMA: Preferred Reporting Items for Systematic Reviews and Meta-analyses; PROSPERO: International prospective register of systematic reviews; RCT: Randomized controlled trial; SPIN: Scleroderma Patient-centered Intervention Network; SSc: Systemic sclerosis; SSLED: Scleroderma Support group Leader EDucation Program; USA: United States of America
\end{abstract}

\section{Funding}

This work was supported by funding from the Canadian Institutes of Health Research (PI Thombs; PJT - 156429). Ms. Turner was supported by a Masters Award from Fonds de Recherche Québec - Santé (FRQ-S). Ms. Rice was supported by a Canadian Institutes for Health Research Vanier Graduate Award. Dr. Thombs was supported by a FRQ-S researcher award. No funding body had any input into any aspect of this manuscript.

\section{Availability of data and materials}

All data and materials can be accessed via the original systematic review report (https://bmjopen.bmj.com/content/6/11/e013325.long/) or from the corresponding author

\section{Authors' contribution}

KAT, DBR, ACJ, JB, and BDT contributed to the conception and design of the systematic review update. JB designed and conducted the database searches. KAT, DBR, ACJ, and BDT were involved in acquisition of data and interpretation of results. KAT and BDT drafted this manuscript. All authors provided critical revisions of the manuscript and approved submission of the final manuscript.

\section{Ethics approval and consent to participate}

Not applicable.

\section{Consent for publication}

Not applicable.

\section{Competing interests}

The authors declare that they have no competing interests.

\section{Publisher's Note}

Springer Nature remains neutral with regard to jurisdictional claims in published maps and institutional affiliations.

\section{Author details \\ 'Lady Davis Institute of the Jewish General Hospital, 4333 Cote Ste Catherine Road, Montréal, Québec H3T 1E4, Canada. ²Department of Psychiatry, McGill University, Montreal, Quebec, Canada. ${ }^{3}$ Department of Psychology, McGill University, Montreal, Quebec, Canada. ${ }^{4}$ Schulich Library of Science and Engineering, McGill University, Montreal, Quebec, Canada. ${ }^{5}$ Department of Medicine, McGill University, Montreal, Quebec, Canada. ${ }^{6}$ Department of Educational and Counselling Psychology, Montreal, Quebec, Canada. ${ }^{7}$ Department of Epidemiology, Biostatistics, and Occupational Health, McGill University, Montreal, Quebec, Canada.}

Received: 20 February 2019 Accepted: 25 February 2019

Published online: 05 March 2019

\section{References}

1. Ussher J, Kristen L, Butow P, et al. What do cancer support groups provide which other supportive relationships do not? The experience of peer support groups for people with cancer. Soc Sci Med. 2006;62:2565-76

2. Docherty A. Experience, functions and benefits of a cancer support group. Patient Educ Couns. 2004;55:87-93.

3. Yaskowich KM, Stam HJ. Cancer narratives and the cancer support group. J Health Psychol. 2003;8:720-37.
4. Zordan RD, Juraskova I, Butow PN, et al. Exploring the impact of training on the experience of Australian support group leaders: current practices and implications for research. Health Expect. 2010;13:427-40.

5. Butow $P$, Ussher J, Kirsten $L$, et al. Sustaining leaders of cancer support groups: the role, needs, and difficulties of leaders. Soc Work Health Care. 2005;42:39-55.

6. Kwakkenbos $L$, Jewett $L R$, Baron $M$, et al. The Scleroderma Patient-centered Intervention Network (SPIN): protocol for a cohort multiple randomised controlled trial (cmRCT) design to support trials of psychosocial and rehabilitation interventions in a rare disease context. BMJ Open. 2013;3: eoo3563.

7. Reimann A, Bend J, Dembski B. Patient-centred care in rare diseases: a patient organisations' perspective. Bundesgesundheitsblatt Gesundheitsforschung Gesundheitsschutz. 2007;50:1484-93.

8. Delisle VC, Gumuchian ST, Kloda L, Boruff J, El-Baalbaki G, Körner A, Malcarne VL, Thombs BD, Scleroderma Support Group Project Advisory Team. The effect of support group peer-facilitator training programs to improve peer-facilitator and support group member outcomes: a systematic review. BMJ Open. 2016;6:e013325.

9. Zordan R, Butow P, Kirsten L, et al. Supporting the supporters: a randomized controlled trial of interventions to assist the leaders of cancer support groups. J Community Psychol. 2015;43:261-77.

10. Seibold J. Scleroderma. In: Harris ED, Budd RC, Firestein GS, Genovese MS, Sergent JS, Ruddy S, et al., editors. Kelly's Textbook of Rheumatology. Philadelphia: Elsevier; 2005. p. 1279-308.

11. Mayes M. Systemic sclerosis: clinical features. In: Klippel JH, Stone JH, Crafford LJ, White PH, editors. Primer on the rheumatic diseases. 13th ed. New York: Springer and Arthritis Foundation; 2008. p. 343-50.

12. Wigley FM, Hummers LK. Clinical features of systemic sclerosis. In: Hochberg MC, Silman AJ, Smolen JS, Weinblatt ME, Weismann WH, editors. Rheumatology. 3rd ed. Philadelphia: Mosby; 2003. p. 1463-80.

13. Delisle VC, Gumuchian ST, Pelaez S, et al. Reasons for non-participation in scleroderma support groups. Clin Exp Rheumatol. 2016;100:56-62.

14. Delisle VC, Gumuchian ST, Rice DB, et al. Perceived benefits and factors that influence the ability to establish and maintain patient support groups in rare diseases: a scoping review. Patient. 2017;10(3):283-93.

15. Delisle VC, Gumuchian ST, El-Baalbaki G, et al. Training and support needs of scleroderma support group facilitators: the North American Scleroderma Support Group Facilitators Survey. Disabil Rehabil. 2018:25:1-6.

16. Gumuchian ST, Delisle VC, Kwakkenbos L. Reasons for attending support groups and organizational preferences: the European Scleroderma Support Group Members Survey. Disabil Rehabil. 2017;19:1-9.

17. Gumuchian ST, Delisle VC, Peláez S, et al. Reasons for not participating in scleroderma patient support groups: a cross-sectional study. Arthritis Care Res. 2018;70:275-83.

18. Scleroderma Society of Canada. Find a support group. www.scleroderma.ca/ Support/Find-A-Support-Group.php. Accessed September 3, 2018.

19. Scleroderma Foundation. Support groups. www. scleroderma.org/site/ PageServer?pagename=patients_supportgroups\#.Vbec7RZvdFw. Accessed September 3, 2018.

20. Thombs BD, Jewett $L R$, Assassi $S$, et al. New directions for patient-centered care in scleroderma. The Scleroderma Patient-centered Intervention Network. Clin Exp Rheumatol. 2012;30:S23-9.

21. Boud D, Feletti G. The challenge of problem-based learning (2nd ed). London: Kogan Page; 1997.

22. Duch BJ, et al. Why problem-based learning? A case study of institutional change in undergraduate education. In: Duch BJ, Groh SE, Allen DE, editors. The power or problem-based learning. Sterling: Stylus; 2001. p. 3-11.

Ready to submit your research? Choose BMC and benefit from:

- fast, convenient online submission

- thorough peer review by experienced researchers in your field

- rapid publication on acceptance

- support for research data, including large and complex data types

- gold Open Access which fosters wider collaboration and increased citations

- maximum visibility for your research: over $100 \mathrm{M}$ website views per year

At BMC, research is always in progress.

Learn more biomedcentral.com/submissions 